\title{
HUBUNGAN POLA ASUH ORANG TUA DENGAN KEPRIBADIAN REMAJA DI SEKOLAH MENENGAH PERTAMA NEGERI 1 REMBOKEN
}

\author{
Natasya G. E. Labaiga \\ Josef Tuda \\ Rina Kundre \\ Program Studi Ilmu Keperawatan Fakultas Kedokteran \\ Universitas Sam Ratulangi \\ Email : natasya.labaiga@gmail.com
}

\begin{abstract}
Abstrack: Adolescent is a situation for looking identity and shape of personality. The factors that greatly influence personality are parenting system. Various parenting system provided by parents is authoritarian, democratic, and permissive that can determine personality for their children later. Personality can be seen based on Big five personality. The purpose of this research was to determine the relations between parenting style with personality in adolescents at Junior High School 1 Remboken. The research method used cross sectional approach. The respondents consisted of 115 adolescents of IX grade with sampling techniques using simple random sampling techniques. The data collection using a parenting style ang Big five personality questionnaire. Test results of Pearson Chi-square tes obtained were smaller than the significant value of $(\alpha=0,05)$ in the Conscientiouness personality $(\rho=0,000)$, Ekstravertion $(\rho=0,005)$, and Neoriticism $(\rho=0,000)$. Conclusion of the results of this study indicate that there is a relationship between parenting style with Conscientiouness personality, Ekstravertion \& Neoriticism.
\end{abstract}

Keywords : Personality, big five personality, parenting, adolescents

\begin{abstract}
Abstrak : Remaja merupakan masa mencari jati diri dan membentuk kepribadian. Adapun faktor yang sangat berpengaruh besar terhadap kepribadian yaitu pola asuh orang tua. Berbagai bentuk pengasuhan yang diberikan orang tua yaitu Otoriter, demokratis dan permisif menentukan kepribadian anaknya nanti. Kepribadian dapat dilihat berdasarkan Big Five Personality. Tujuan penelitian ini adalah mengetahui hubungan pola asuh orang tua dengan kepribadian pada remaja di SMP Negeri 1 Remboken. Metode penelitian menggunakan pendekatan cross sectional. Responden terdiri dari 115 remaja kelas IX dengan teknik pengambilan sampel simple random sampling. Pengumpulan data menggunakan kuesioner pola asuh dan kuesioner Big Five Personality. Hasil Uji uji Pearson Chi-square yang didapatkan lebih kecil dari nilai signifikan $(\alpha=0,05)$ pada kepribadian Conscientiouness $(\rho=0,000)$, Ekstravertion $(\rho=0,005)$, dan Neoriticism $(\rho=0,000)$. Kesimpulan hasil penelitian ini menunjukkan terdapat hubungan antara pola asuh orang tua dengan kepribadian Conscientiouness, Ekstravertion \& Neoriticism.
\end{abstract}

Kata kunci : Kepribadian, big five personality, pola asuh, remaja 


\section{PENDAHULUAN}

Remaja diartikan sebagai masa dimana terjadi proses peralihan dari masa kanak-kanak ke masa dewasa. Selain kematangan fisik dan seksual, remaja juga mengalami tahapan menuju kemandirian sosial, ekonomi, membangun identitas diri, serta kemampuan bernegosiasi (WHO, 2015). Badan Kependudukan dan Keluarga Berencana Nasional, menyatakan rentang usia disaat remaja adalah 10-24 tahun dan belum menikah. WHO menjelaskan jumlah kelompok remaja di dunia saat ini mencapai 1,2 Milyar atau $18 \%$ dari jumlah penduduk dunia. Jumlah kelompok remaja di Indonesia menurut Sensus Penduduk 2010 sebanyak 43,5 atau sekitar $18 \%$. Badan Pusat Statistik (2010) menunjukkan bahwa jumlah kelompok umur remaja di indonesia berkisar 43,55 juta jiwa. Di Sulawesi utara melalui BPS (2010), menunjukkan bahwa jumlah remaja sebanyak 17,61\% atau 399.722 jiwa.

Masa remaja merupakan masa yang sangat rawan terjerumus dalam segala bentuk kenakalan remaja. Kenakalan terjadi karena kegagalan dalam perkembangan jiwanya (Amanda, dkk, 2017). Komisi Nasional Perlindungan Anak pada tahun 2013 mencatat bahwa ada 255 kasus tawuran yang dilakukan oleh remaja. Hasil penelitian dari Badan Narkotika Nasional didapatkan data bahwa penyalahgunaan Narkoba yang dilakukan remaja sebesar $1,5 \%$ dari populasi yang ada. Kepribadian biasanya dihubungkan dengan ciri-ciri tertentu yang muncul pada setiap individu. Kepribadian remaja dipengaruhi oleh berbagai faktor seperti budaya, keadaan fisik, kematangan biologis dan yang sangat berpengaruh besar bagi kepribadian remaja adalah pola asuh orang tua karena keluarga merupakan lingkungan sosial pertama oleh seorang anak untuk bertumbuh dan berkembang (Yanti \& Nasution, 2012). Orang tua memiliki pilihan berbeda-beda dalam menerapkan pola asuh untuk memberi bimbingan terhadap proses perkembangan anak mereka. Pola asuh orangtua dibagi menjadi 3, yaitu pola asuh otoriter, demokratis, dan permisif (Munita, 2017). Penelitian sebelumnya oleh Christinna, dkk, (2017) tentang "Hubungan Pola Asuh Orang Tua Dengan Identitas Diri Pada Remaja Di SMP Negeri 1 Tempel Yogyakarta Tahun 2017" menunjukkan bahwa sebagian besar orangtua dengan jumlah 83 Responden dari sampel yaitu 130 responden memberikan pola asuh demokratis dan tingkat Identitas diri pada remaja di SMP Negeri 1 Tempel Yogyakarta masuk dalam kategori baik dengan jumlah 104 responden. Sehingga, menunjukkan adanya hubungan yang signifikan antara Pola asuh orangtua dengan Identitas diri pada remaja. Sugianto, G (2015) meneliti tentang "Pengaruh Persepsi pola asuh orang tua dan tipe kepribadian Big Five terhadap kecerdasan emosi pada remaja" menunjukkan bahwa terdapat pengaruh yang signifikan secara keseluruhan dari pola asuh (otoriter, demokratis, permisif) dan kepribadian Big Five (Ekstravertion, Agreeableness, Conscientiouness, Neoriticism, dan Openess) terhadap kecerdasan emosi remaja.

$$
\text { Studi pendahuluan melalui }
$$
wawancara pada siswa kelas IX di SMP Negeri 1 Remboken yang dilakukan pada 30 siswa, didapatkan data bahwa kebanyakan orang tua menerapkan pola asuh demokratis yaitu orang tua memberikan kebebasan kepada anak untuk memilih apa saja yang ingin dilakukan, namun orang tua tetap akan mengawasi anak tersebut bahkan orang tua tidak segan-segan untuk memberikan hukuman kepada anak jika anak tersebut melakukan suatu kesalahan (Munita, 2017). Saling terbuka dalam hubungan antara orang tua dan anak sangat dibutuhkan dalam proses perkembangan kepribadian remaja. Pola asuh yang diterapkan orang tua dapat membuat remaja semakin percaya diri dan mandiri. Namun, kenyataan yang terjadi sekarang, meskipun orang tua telah memberikan pola asuh yang baik. Ternyata kepribadian remaja tidak sesuai dengan 
harapan dari orang tua (Putri A, 2010). Dilihat dari fenomena yang terjadi saat ini, pola asuh yang diberikan orang tua akan berdampak pada perubahan kepribadian remaja. Sehingga, berdasarkan hal diatas saya tertarik untuk melakukan penelitian mengenai "Hubungan Pola Asuh Orang Tua Dengan Kepribadian Remaja”.

\section{METODE PENELITIAN}

Penelitian ini termasuk dalam jenis penelitian kuantitatif dengan menganalisis gambaran hubungan antara kedua variabel yaitu variabel independen (Pola asuh orang tua) dan variabel dependen (Kepribadian remaja). Penelitian ini menggunakan desain penelitian cross sectional. Penelitian ini dilaksanakan di SMP Negeri 1 Remboken pada tanggal 31 November 2018. Populasi penelitian ini adalah seluruh kelas IX dengan jumlah 163. Pengambilan sampel menggunakan teknik Simple random sampling dengan rumus slovin maka didapatkan jumlah sampel minimal 115 remaja. Instrumen penelitian yang digunakan untuk mengukur variabel pola asuh orang tua menggunakan kuesioner yang digunakan sebelumnya oleh Devi, C (2012) yang telah diuji validitasnya. kuesioner ini terdiri dari 27 pertanyaan. 9 pertanyaan untuk pola asuh demokratis , 9 pertanyaan untuk pola asuh otoriter dan 9 pertanyaan untuk pola asuh permisif dengan kriteria skor dan pilihan $1=$ sangat tidak setuju, $2=$ tidak setuju, $3=$ setuju , 4= sangat setuju. Setelah lembar kuesioner diisi oleh responden, kemudian dilakukan penghitungan skor dengan cara menjumlahkan skor tiap pertanyaan. Untuk menentukan jenis pola asuh yang diterapkan oleh orang tua dilihat dari skor tertinggi.

Pengukuran Kepribadian remaja menggunakan kuesioner yang digunakan sebelumnya oleh Widyahastuti (2016) dengan kriteria skor $1=$ sangat tidak sesuai, $2=$ tidak sesuai, $3=$ sesuai , $4=$ sangat sesuai untuk favorable, dan sebaliknya untuk unfavorable. Cara penilaiannya dengan kategori $\mathrm{X} \geq$ Median=Positif \& $\mathrm{X}$ $<$ Median=Negatif.

Pengolahan data yang diperoleh dari hasil penelitian ini diolah secara manual dengan mengelompokkan hasil wawancara dan observasi kemudian dilakukan penghitungan skor dan dianalisis menggunakan uji statistik melalui sistem komuterisasi dengan beberapa tahap yaitu editing, coding, entering, cleaning (Notoatmodjo, 2012). Analisa bivariat dalam penelitian ini yaitu untuk mengetahui hubungan pola asuh orang tua dengan kepribadian remaja di SMP Negeri 1 Remboken. Peneliti menggunakan uji statistic Pearson Chi Square dengan tingkat kemaknaan $95 \%(\alpha=0,05)$.

\section{HASIL dan PEMBAHASAN}

1. Karakteristik Responden

Tabel 1. Distribusi Responden Berdasarkan Jenis Kelamin

\begin{tabular}{ccc}
\hline Jenis Kelamin & $\mathbf{n}$ & $\mathbf{\%}$ \\
\hline Laki-laki & 55 & 47,8 \\
Perempuan & 60 & 52,2 \\
\hline Total & $\mathbf{1 1 5}$ & $\mathbf{1 0 0}$ \\
\hline
\end{tabular}

Sumber : Data Primer 2019

Berdasarkan Jenis kelamin, diperoleh mayoritas responden adalah berjenis kelamin perempuan (52,2\%). Hasil penelitian ini sejalan dengan penelitian Widyahastuti (2016). Pada umumnya remaja putri lebih cepat pertumbuhan fisiknya dibandingkan lakilaki (Ali \& Asrori, 2017). Perempuan lebih mudah berempati pada lingkungan dibandingkan laki-laki (Christinna, dkk, 2017).

Tabel 2. Distribusi Responden Berdasarkan Usia

\begin{tabular}{ccc}
\hline Usia & n & \% \\
\hline 13 Tahun & 63 & 54,8 \\
14 Tahun & 43 & 37,4 \\
15 Tahun & 9 & 7,8 \\
\hline Total & $\mathbf{1 1 5}$ & $\mathbf{1 0 0}$ \\
\hline
\end{tabular}

Sumber : Data Primer 2019 
Hasil penelitian menunjukkan bahwa mayoritas responden berusia 13 tahun $(54,8 \%)$. Masa remaja berlangsung antara 12 tahun sampai dengan 21 tahun bagi wanita dan 13 tahun sampai dengan 22 tahun bagi pria. Remaja adalah fase "mencari jati diri" (Ali \& Asrori, 2017). Semakin bertambahnya usia seseorang maka semakin bertambah pula pola pikirnya. Sehingga, sangatlah penting perhatian yang diberikan orang tua karena hal itu yang akan membentuk kepribadian anak tersebut (Christinna, dkk, 2017).

Tabel 3. Distribusi Responden Berdasarkan Tempat Tinggal

\begin{tabular}{ccc}
\hline Tempat Tinggal & $\mathbf{n}$ & \% \\
\hline Rumah sendiri & 107 & 93,0 \\
Kost & 4 & 3,5 \\
Menumpang & 4 & 3,5 \\
\hline Total & $\mathbf{1 1 5}$ & $\mathbf{1 0 0}$ \\
\hline
\end{tabular}

Sumber : Data Primer 2019

Hasil analisa menunjukkan mayoritas responden bertempat tinggal rumah sendiri $(93,0 \%)$. Hubungan sosial terjadi dimulai dari lingkungan rumah sendiri, kemudian berkembang luas ke lingkungan sekolah dan lingkungan masyarakat (Ali \& Asrori, 2017).

\section{Analisa Univariat}

Tabel 4. Distribusi Responden Berdasarkan Pola Asuh Orang Tua

\begin{tabular}{ccc}
\hline Pola asuh & $\mathbf{n}$ & $\mathbf{\%}$ \\
\hline Otoriter & 20 & 17,4 \\
Demokratis & 81 & 70,4 \\
Permisif & 14 & 12,2 \\
\hline Total & $\mathbf{1 1 5}$ & $\mathbf{1 0 0}$ \\
\hline
\end{tabular}

Sumber : Data Primer 2019

Tabel 4 menunjukkan bahwa mayoritas responden orang tuanya menerapkan pola asuh demokratis $(70,4 \%)$ Hasil penelitian ini sesuai dengan Christinna,dkk (2017) menunjukkan dari jumlah responden 130 orang, pola asuh demokratis memiliki jumlah terbanyak yaitu 83 orang. Hal ini menunjukkan bahwa pola asuh demokratis banyak diterapkan orang tua dalam mendidik anak mereka. Pola asuh dimana adanya sikap terbuka antara orang tua dengan anaknya (Ilham, 2013). Orang tua tetap memberikan kebebasan namun juga tetap memberikan batasan untuk mengarahkan anak dalam menentukan dan mengambil suatu keputusan yang tepat di dalam hidupnya. (Amin \& Harianti, 2018).

Tabel 5. Distribusi Responden Berdasarkan Kepribadian Openess

\begin{tabular}{ccc}
\hline Kepribadian Openess & $\mathbf{n}$ & \% \\
\hline Positif & 65 & 56,5 \\
Negatif & 50 & 43,5 \\
\hline Total & $\mathbf{1 1 5}$ & $\mathbf{1 0 0}$ \\
\hline
\end{tabular}

Sumber : Data Primer 2019

Berdasarkan hasil menunjukkan mayoritas responden memiliki Kepribadian Openess yang positif (56,6\%). Seseorang yang cenderung berkepribadian Openess positif memiliki rasa ingin tahu yang tinggi dan dapat memberikan ide-ide baru yang tidak biasa serta memiliki sikap yang lebih positif untuk belajar (Widyasari, 2017).

Tabel 6. Distribusi Responden Berdasarkan Kepribadian Conscientiouness

\begin{tabular}{ccc}
\hline Kepribadian Conscientiouness & $\mathbf{n}$ & $\mathbf{\%}$ \\
\hline Positif & 54 & 47,0 \\
Negatif & 61 & 53,0 \\
\hline Total & $\mathbf{1 1 5}$ & $\mathbf{1 0 0}$ \\
\hline
\end{tabular}

Sumber : Data Primer 2019

Hasil analisa menunjukkan mayoritas responden memiliki Kepribadian Conscientiouness yang negatif $(53,0 \%)$. Seseorang yang cenderung berkepribadian Conscientiouness negatif memiliki karakter yang tidak berhati-hati dan lebih suka secara spontan daripada merencanakan segala sesuatu terlebih dahulu (Kapusuz \& Cavus, 2018).

Tabel 7. Distribusi Responden Berdasarkan Kepribadian Ekstravertion

\begin{tabular}{ccc}
\hline Kepribadian Ekstravertion & $\mathbf{n}$ & $\mathbf{\%}$ \\
\hline Positif & 67 & 58,3 \\
Negatif & 48 & 41,7 \\
\hline Total & $\mathbf{1 1 5}$ & $\mathbf{1 0 0}$ \\
\hline
\end{tabular}

Sumber : Data Primer 2019 
Tabel 7 menunjukkan mayoritas responden memiliki Kepribadian Ekstravertion yang positif (58,3\%). Seseorang yang cenderung berkepribadian Ekstravertion positif suka bersosialisasi \& pemikiran yang fleksibel (Ercan, 2017).

Tabel 8. Distribusi Responden Berdasarkan Kepribadian Agreeableness

\begin{tabular}{ccc}
\hline Kepribadian Agreeableness & n & \% \\
\hline Positif & 69 & 60,0 \\
Negatif & 46 & 40,0 \\
\hline Total & $\mathbf{1 1 5}$ & $\mathbf{1 0 0}$ \\
\hline Sumber
\end{tabular}

Sumber : Data Primer 2019

Hasil penelitian menunjukkan mayoritas responden memiliki Kepribadian Agreeableness yang positif (60,0\%). Seseorang yang cenderung berkepribadian Agreeableness positif memiliki sifat suka menolong (Widyasari, dkk, 2017), dan sangat diterima oleh lingkungan sosialnya (Ercan, 2017).

Tabel 9. Distribusi Responden Berdasarkan Kepribadian Neoriticism

\begin{tabular}{ccc}
\hline Kepribadian Neoriticism & $\mathbf{n}$ & $\mathbf{\%}$ \\
\hline Positif & 69 & 60,0 \\
Negatif & 46 & 40,0 \\
\hline Total & $\mathbf{1 1 5}$ & $\mathbf{1 0 0}$ \\
\hline
\end{tabular}

Sumber : Data Primer 2019

Tabel 9 menunjukkan mayoritas responden memiliki Kepribadian Neoriticism yang positif (60,0\%). Seseorang yang cenderung berkepribadian Neoriticism positif memiliki sifat mandiri dan pengalaman hidup yang luas (Gallego \& Prado, 2014).

\section{Analisa Bivariat}

Tabel 10. Hubungan Pola Asuh Orang Tua Dengan Kepribadian Openess

\begin{tabular}{ccccccccc}
\hline & \multicolumn{3}{c}{ Kepribadian Openess } & \multirow{2}{*}{ Total } & \multirow{2}{*}{ Pv } \\
\cline { 2 - 6 } Pola Asuh & \multicolumn{2}{c}{ Positif } & \multicolumn{2}{c}{ Negatif } & & & \\
\cline { 2 - 6 } & $\mathrm{n}$ & $\%$ & $\mathrm{n}$ & $\%$ & $\mathrm{n}$ & $\%$ & \\
\hline Otoriter & 14 & 12,2 & 6 & 5,2 & 20 & 100 & \\
Demokratis & 43 & 37,4 & 38 & 33,0 & 81 & 100 & 0,393 \\
Permisif & 8 & 7,0 & 6 & 5,2 & 14 & 100 & \\
\hline Total & $\mathbf{6 5}$ & $\mathbf{5 6 , 5}$ & $\mathbf{5 0}$ & $\mathbf{4 3 , 5}$ & $\mathbf{1 1 5}$ & $\mathbf{1 0 0}$ & \\
\hline Sumber : & Data & Primer & $\mathbf{2 0 1 9}$ & & &
\end{tabular}

Analisa hubungan antara pola asuh orang tua dengan kepribadian Openess remaja di SMP Negeri 1 Remboken dengan hasil uji Pearson Chi square dengan taraf signifikasi $\alpha=5 \%$ diperoleh $\rho$ value $=0,393>0,05$. Hal ini menunjukkan tidak terdapat hubungan yang signifikan antara pola asuh orang tua dengan kepribadian Openess remaja di SMP Negeri 1 Remboken. Hasil penelitian ini, orang tua yang menerapkan pola asuh otoriter, demokratis, dan permisif memiliki remaja dengan kepribadian Openess yang positif. Hasil ini bertentangan dengan penelitian sebelumnya oleh Purnamasari (2016) dimana terdapat pengaruh pola asuh orang tua terhadap keterbukaan diri remaja.

Pola asuh merupakan cara orang tua berinteraksi dengan anaknya (Amin \& Harianti, 2018). Pola asuh bukan satusatunya faktor yang mutlak mempengaruhi keterbukaan diri seseorang. Namun, adapun faktor seperti perbedaan jenis kelamin. Pada penelitian Ditya (2013) terdapat perbedaan keterbukaan diri melalui media facebook yang ditinjau dari jenis kelamin, yang menunjukkan bahwa keterbukaan diri pada wanita lebih tinggi dibandingkan pada pria. Dan ada juga faktor-faktor lain yang bisa mempengaruhi keterbukaan diri seseorang yaitu keterbukaan timbal balik, perasaan saling menerima, dan permintaan untuk terbuka (Hargie, 2006).

Tabel 11. Hubungan Pola Asuh Orang Tua Dengan Kepribadian Conscientiouness

\begin{tabular}{|c|c|c|c|c|c|c|c|}
\hline \multirow{3}{*}{ Pola Asuh } & \multicolumn{4}{|c|}{ Kepribadian Conscientiouness } & \multirow{2}{*}{\multicolumn{2}{|c|}{ Total }} & \multirow{3}{*}{ Pv } \\
\hline & \multicolumn{2}{|c|}{ Positif } & \multicolumn{2}{|c|}{ Negatif } & & & \\
\hline & $\mathrm{n}$ & $\%$ & $\mathrm{n}$ & $\%$ & $\mathrm{n}$ & $\%$ & \\
\hline Otoriter & 16 & 13,9 & 4 & 3,5 & 20 & 100 & \\
\hline Demokratis & 28 & 24,3 & 53 & 46,1 & 81 & 100 & 0,000 \\
\hline Permisif & 10 & 8,7 & 4 & 3,5 & 14 & 100 & \\
\hline Total & 54 & 47,0 & 61 & 53,0 & 115 & 100 & \\
\hline
\end{tabular}

Sumber : Data Primer 2019

Hasil crosstab mengenai hubungan antara pola asuh orang tua dengan 
kepribadian Conscientiouness remaja di SMP Negeri 1 Remboken dengan hasil uji Pearson Chi square dengan taraf signifikasi $\alpha=5 \%$ diperoleh $\rho$ value $=$ $0,000<0,05$. Hal ini menunjukkan terdapat hubungan yang signifikan antara pola asuh orang tua dengan kepribadian Conscientiouness remaja di SMP Negeri 1 Remboken. Hasil penelitian ini, orang tua yang menerapkan pola asuh demokratis memiliki remaja dengan kepribadian Conscientiouness negatif sedangkan yang menerapkan pola asuh otoriter dan permisif memiliki remaja dengan kepribadian Conscientiouness positif. Penelitian sebelumnya oleh Fuadiah, dkk (2014) menunjukkan seseorang yang diasuh dengan pola asuh otoriter akan lebih berhati-hati dan disiplin, sedangkan seseorang yang diasuh dengan pola asuh demokratis dan permisif karena terbiasa dengan kebebasan yang diberikan, maka mereka sulit untuk disiplin, ceroboh, dan tidak konsisten.

Tabel 12. Hubungan Pola Asuh Orang Tua Dengan Kepribadian Ekstravertion

\begin{tabular}{lccccccc}
\hline & \multicolumn{3}{c}{ Kepribadian } & \multicolumn{2}{c}{ Ekstravertion } & \multirow{2}{*}{ Total } & \multirow{2}{*}{ Pv } \\
\cline { 2 - 5 } Pola Asuh & \multicolumn{2}{c}{ Positif } & \multicolumn{2}{l}{ Negatif } & & & \\
\cline { 2 - 6 } & $\mathrm{n}$ & $\%$ & $\mathrm{n}$ & $\%$ & $\mathrm{n}$ & $\%$ & \\
\hline Otoriter & 7 & 6,1 & 13 & 11,3 & 20 & 100 & \\
Demokratis & 55 & 47,8 & 26 & 22,6 & 81 & 100 & 0,005 \\
Permisif & 5 & 4,3 & 9 & 7,8 & 14 & 100 & \\
\hline Total & $\mathbf{6 7}$ & $\mathbf{5 8 , 3}$ & $\mathbf{4 8}$ & $\mathbf{4 1 , 7}$ & $\mathbf{1 1 5}$ & $\mathbf{1 0 0}$ & \\
\hline
\end{tabular}

Sumber : Data Primer 2019

Hasil analisa hubungan antara pola asuh orang tua dengan kepribadian Ekstravertion remaja di SMP Negeri 1 Remboken dengan hasil uji Pearson Chi square dengan taraf signifikasi $\alpha=5 \%$ diperoleh $\rho$ value $=0,005<0,05$. Hal ini menunjukkan terdapat hubungan yang signifikan antara pola asuh orang tua dengan kepribadian Ekstravertion remaja di SMP Negeri 1 Remboken. Hasil penelitian ini, orang tua yang menerapkan pola asuh demokratis memiliki remaja dengan kepribadian Ekstravertion positif, sedangkan orang tua yang menerapkan pola asuh otoriter dan permisif memiliki remaja dengan kepribadian Ekstravertion negatif. Pola asuh mempengaruhi pembentukan dan perkembangan kepribadian anak (Afrilyanti, Herlina \& Rahmalia, 2015). Pola asuh demokratis yang diterapkan orang tua akan memberikan wawasan berpikir, bertindak, dan bersosialisasi yang baik sehingga memicu perkembangan sosial remaja menjadi pribadi yang percaya diri dan lebih terbuka (Pertiwi, Hendro \& Kallo, 2016). Berbeda dengan orang tua yang memberikan pola asuh otoriter akan menjadikan anaknya tidak percaya diri, dan tidak terbuka. Hal ini didukung oleh penelitian sebelumnya oleh Hikmah (2015) bahwa anak yang diasuh dengan pola asuh otoriter akan cenderung tidak yakin dengan dirinya sendiri. Dan orang tua yang memberikan pola asuh permisif menjadikan anaknya manja, dan tidak bertanggung jawab. Hal ini didukung oleh penelitian sebelumnya oleh Budisetyani (2014) bahwa adanya hubungan antara pola asuh permisif ibu dengan perilaku merokok pada remaja.

Tabel 13. Hubungan Pola Asuh Orang Tua Dengan Kepribadian Agreeableness

\begin{tabular}{lccccccc}
\hline & \multicolumn{3}{c}{ Kepribadian } & \multicolumn{2}{c}{ Agreeableness } & \multirow{2}{*}{ Total } & \multirow{2}{*}{ Pv } \\
\cline { 2 - 5 } Pola Asuh & \multicolumn{2}{c}{ Positif } & \multicolumn{2}{l}{ Negatif } & & & \\
\cline { 2 - 6 } & $\mathrm{n}$ & $\%$ & $\mathrm{n}$ & $\%$ & $\mathrm{n}$ & $\%$ & \\
\hline Otoriter & 10 & 8,7 & 10 & 8,7 & 20 & 100 & \\
Demokratis & 51 & 44,3 & 30 & 26,1 & 81 & 100 & 0,555 \\
Permisif & 8 & 7,0 & 6 & 5,2 & 14 & 100 & \\
\hline Total & $\mathbf{6 9}$ & $\mathbf{6 0 , 0}$ & $\mathbf{4 6}$ & $\mathbf{4 0 , 0}$ & $\mathbf{1 1 5}$ & $\mathbf{1 0 0}$ & \\
\hline
\end{tabular}

Sumber : Data Primer 2019

Hasil crosstab mengenai hubungan antara pola asuh orang tua dengan kepribadian Agreeableness remaja di SMP Negeri 1 Remboken dengan hasil uji Pearson Chi square dengan taraf signifikasi $\alpha=5 \%$ diperoleh $\rho$ value = $0,555>0,05$. Hal ini menunjukkan tidak terdapat hubungan yang signifikan antara pola asuh orang tua dengan kepribadian Agreeableness remaja di SMP Negeri 1 Remboken. Hasil penelitian ini, orang tua 
yang menerapkan pola asuh pola asuh demokratis dan permisif memiliki remaja dengan kepribadian Agreeableness positif, sedangkan orang tua yang menerapkan pola asuh otoriter memiliki remaja dengan kepribadian Agreeableness yang jumlahnya seimbang antara positif dan negatif.

Sikap yang diberikan orang tua yaitu memberikan kebebasan anak untuk memilih hal-hal yang diinginkan untuk mengembangkan seluruh aspek kemampuan dirinya, hal itulah yang menyebabkan remaja memiliki kemampuan sosialisasi yang baik (Lestiawati, 2013). Bukan hanya pola asuh yang dapat mempengaruhi kepribadian Agreeableness seseorang, namun ada juga faktor lain seperti budaya. Peran budaya merupakan dasar kehidupan sosial seseorang. Budaya mencakup perbuatan, aktivitas sehari-hari, pola berpikir, kepercayaan, dan ideologi yang dilakukan oleh masyarakat. Budaya dapat dijadikan panduan dalam membentuk mental dan media untuk bertukar pikiran (Pratama, 2011).

Tabel 14. Hubungan Pola Asuh Orang Tua Dengan Kepribadian Neoriticism

\begin{tabular}{lccccccc}
\hline & \multicolumn{3}{c}{ Kepribadian Neoriticism } & \multicolumn{2}{c}{ Total } & \multirow{2}{*}{ Pv } \\
\cline { 2 - 6 } Pola Asuh & \multicolumn{2}{c}{ Positif } & \multicolumn{2}{l}{ Negatif } & & & \\
\cline { 2 - 6 } & $\mathrm{n}$ & $\%$ & $\mathrm{n}$ & $\%$ & $\mathrm{n}$ & $\%$ & \\
\hline Otoriter & 6 & 5,2 & 14 & 12,2 & 20 & 100 & \\
Demokratis & 59 & 51,3 & 22 & 19,1 & 81 & 100 & 0,000 \\
Permisif & 4 & 3,5 & 10 & 8,7 & 14 & 100 & \\
\hline Total & $\mathbf{6 9}$ & $\mathbf{6 0 , 0}$ & $\mathbf{4 6}$ & $\mathbf{4 0 , 0}$ & $\mathbf{1 1 5}$ & $\mathbf{1 0 0}$ & \\
\hline
\end{tabular}

Sumber : Data Primer 2019

Analisa hubungan antara pola asuh orang tua dengan kepribadian Neoriticism remaja di SMP Negeri 1 Remboken dengan hasil uji Pearson Chi square dengan taraf signifikasi $\alpha=5 \%$ diperoleh $\rho$ value $=0,000<0,05$. Hal ini menunjukkan terdapat hubungan yang signifikan antara pola asuh orang tua dengan kepribadian Neoriticism remaja di SMP Negeri 1 Remboken. Hasil penelitian ini, orang tua yang menerapkan pola asuh demokratis memiliki remaja dengan kepribadian Neoriticism positif yaitu remaja yang mampu mengontrol emosi (Ercan, 2017). Sedangkan, orang tua yang menerapkan pola asuh otoriter dan permisif memiliki remaja dengan kepribadian Neoriticism negatif yaitu remaja yang temperamental, mudah marah dan mudah tersinggung (Widyasari, dkk, 2017). Penelitian ini sejalan dengan penelitian yang dilakukan oleh Fellasari \& Lestari (2016) yang menyatakan bahwa orang tua yang menerapkan pola asuh demokratis akan memberikan pengaruh positif terhadap kestabilan emosi remaja, dikarenakan remaja diasuh dan diajarkan untuk menghindari permusuhan. Berbeda dengan orang tua yang menerapkan pola asuh otoriter akan menjadikan anaknya berperilaku berlandaskan emosi. Dan orang tua yang menerapkan pola asuh permisif menyebabkan anaknya tidak bisa mengontrol dirinya dengan baik, cenderung agresif, dan sering mengalami permusuhan.

\section{SIMPULAN}

Faktor yang sangat mempengaruhi kepribadian remaja adalah pola asuh orang tua. Orang tua memiliki berbagai pilihan dalam cara mengasuh, mendidik, dan membimbing anak. Ada 3 bentuk pola asuh yang dapat digunakan orang tua yaitu pola asuh otoriter, demokratis, dan permisif. Dalam penelitian ini mayoritas orang tua menerapkan pola asuh demokratis dalam mendidik anak mereka. Pola asuh demokratis yang diberikan orang tua mampu mengubah kepribadian anaknya berdasarkan Big Five Personality. Dalam penelitian ini, remaja memiliki Kepribadian Openess, Ekstravertion, Agreeableness, dan Neoriticism yang cenderung positif, serta kepribadian Conscientiouness yang cenderung negatif.

\section{DAFTAR PUSTAKA}

Afrilyanti, Herlina \& Rahmalia. (2015). Hubungan pola asuh orang tua dengan status identitas diri remaja. 
Jurnal Program Studi Ilmu Keperawatan Universitas Riau.

Ali Mohammad \& Asrori Mohammad. (2017). Psikologi Remaja. Jakarta : PT Bumi Aksara.

Amanda, M. P, Humaedi, S \& Santoso, M.B. (2017). Penyalahgunaan Narkoba di kalangan Remaja (Adolescent Substance Abuse). Volume 4, Nomor 2. Jurnal Onliner Universitas Padjadjaran Bandung.

Amin, S, \& Harianti, R. (2018). Pola Asuh Orang tua Dalam Motivasi Belajar Anak. Yogyakarta : Deepublish.

Badan Pusat Statistik. (2010). Hasil sensus penduduk.

Budisetyani, W. (2014). Pola Asuh Permisif Ibu Dan Perilaku Merokok Pada Remaja Laki-Laki Di SMA Negeri 1 Samarapura. Jurnal Psikologi Universitas Udayana.

Christinna M, Nurmaguphita D, \& Rahayu P. (2017). Hubungan Pola Asuh Orang Tua Dengan Identitas Diri Pada Remaja Di SMP Negeri 1 Tempel Yogyakarta Tahun 2017. UNISA DIGITAL LibraryRepository.

Devi, C. (2012). Hubungan pola asuh orang tua dengan kecerdasan sosial pada siswa kelas VI SD Jatimulyo. Skripsi Fakultas Psikologi Universitas Islam Negeri (UIN) Maulana Malik Ibrahim Malang.

Ditya A, N. (2013). Self Disclosure terhadap pasangan melalui facebook di tinjau dari jenis kelamin. Jurnal Psikologi, Volume 01 No 02, Tahun 2013.

Ercan, H. (2017). The Relationship between Resilience and the Big
Five Personality Traits in Emerging Adulthood. Eurasian Journal of Educational Research.

Fellasari \& Lestari. (2016). Hubungan antara pola asuh orang tua dengan kematangan emosi remaja. Jurnal Fakultas Psikologi Universitas Islam Negeri Sultan Syarif Kasim Riau.

Fuadiah, Anward \& Erlyani. (2014). Peranan Conscientiousness terhadap perilaku cyberloafing pada mahasiswa. Jurnal Fakultas Kedokteran Program studi psikologi Kalimantan Selatan.

Gallego, A \& Prado, S. (2014). The Big Five Personality Traits and Attitudes towards Immigrants. Journal of Ethnic and Migration Studies.

Hargie, O. (2006). Handbook of Communication Skills. Third Edition. New York : Routledge.

Hikmah. (2015). Hubungan Pola Asuh Otoriter Dengan Kepercayaan DiriAnak Di TK ABA 1 Huidu Kecamatan Limboto Barat Kabupaten Gorontalo.Thesis, Department of Early Childhood Education, Faculty of Education, State University of Gorontalo.

Ilham, F. (2013). Hubungan pola asuh orang tua dengan pembentukan kepribadian remaja di SMP Handayani Sungguminasa-gowa. Skripsi Fakultas Ilmu Kesehatan Universitas Islam Negeri Alauddin Makasar.

Kapusuz, Cavus. (2018). How Individuals' Psychological Capital Mediate The Relationship Between Big Five Personality Traits And Burnout.luslararast Sosyal Araștırmalar Dergisi / The Journal 
of International Social ResearchCilt: 11 Sayl: 59 Ekim 2018 Volume: 11 Issue.

Lestiawati, M. (2013). Pengaruh pola asuh orang tua terhadap kemampuan sosial anak. Jurnal FIP Universitas Negeri Jakarta.

Munita, Y. (2017). Jangan Ajari Aku Harga Diri Yang Rendah. Yogyakarta : Psikologi Corner.

Notoadmodjo, Soekodjo. (2012). Metodologi Penelitian Kesehatan. Edisi Revisi. Jakarta : Rineka Cipta.

Pertiwi, E, Bidjuni, H \& Kallo, V. (2016). Hubungan pola asuh orang tua dengan perkembangan sosial (percaya diri) remaja di SMA Negeri 7 Manado. E-journal Keperawatan Universitas Sam Ratulangi Manado Program studi ilmu keperawatan.

Pratama, D. (2011). Peran kebudayaan dalam membentuk kepribadian. Jurnal Gunadarma University.

Purnamasari, E. (2016). Pengaruh pola asuh orang tua terhadap keterbukaan diri remaja kelas $\mathrm{X}$ SMK Negeri 02 Salatiga. Skripsi Universitas Kristen Satya Wacana.

Putri, A. (2010). Hubungan antara kecenderungan pola asuh demokratis ayah dengan kepercayaan diri pada remaja. SKRIPSI Fakultas Psikologi Universitas Muhammadyah Surakarta.

Sugianto, G. (2016). Pengaruh Persepsi pola asuh orang tua dan tipe kepribadian Big Five terhadap kecerdasan emosi pada remaja. Skripsi Fakultas Psikologi
Universitas Islam Negeri Syarif Hidayatullah Jakarta.

WHO. (2015). Adolescent Development Topics at Glance.

Widyahastuti, R. (2016). Pengaruh Kepribadian (Big Five Personality) terhadap Multitasking. Skripsi Fakultas Psikologi Universitas Muhammadiyah Malang.

Widyasari, Prasetyo \& Pusponegoro. (2017). Pengaruh Kepribadian Openess dan Agreeableness Terhadap Intensi Berbagi Pengetahuan Pada Karyawan Perum LPPNPI (AirNav Indonesia) Cabang Madya Surabaya. Jurnal Jurusan Psikologi Universitas Brawijaya, Malang, Indonesia.

Yanti, \& Nasution. (2012). Pola Asuh Keluarga dan Tipe Kepribadian Remaja di SMPN 7 Medan. Jurnal Ilmiah Poltekkes. 